Preprints of the

Max Planck Institute for

Research on Collective Goods

Bonn 2008/14

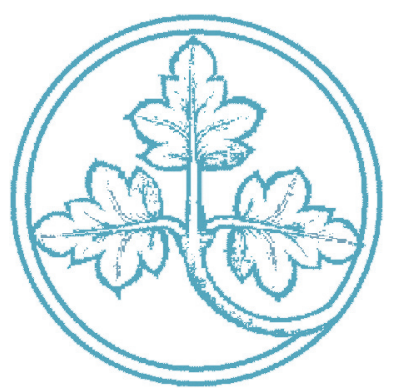

Coherence Shifts in

Probabilistic Inference Tasks

Andreas Glöckner /

Tilmann Betsch / Nicola Schindler

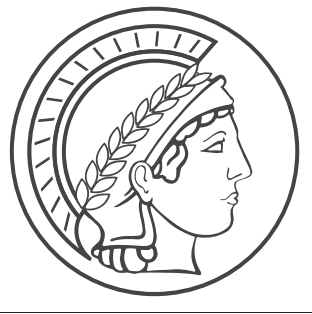




\title{
Coherence Shifts in Probabilistic Inference Tasks
}

\author{
Andreas Glöckner / Tilmann Betsch / Nicola Schindler
}

revised version April 2009 


\title{
Coherence Shifts in Probabilistic Inference Tasks*
}

\author{
Andreas Glöckner \\ Max Planck Institute for Research on Collective Goods \\ Tilmann Betsch/Nicola Schindler \\ University of Erfurt
}

\begin{abstract}
The fast-and-frugal heuristics approach to probabilistic inference assumes that individuals often employ simple heuristics to integrate cue information that commonly function in a nonreciprocal fashion. Specifically, the subjective validity of a certain cue remains stable during the application of a heuristic and is not changed by the presence or absence of another cue. The parallel-constraint-satisfaction model, in contrast, predicts that information is processed in a reciprocal fashion. Specifically, it assumes that subjective cue validities interactively affect each other and are modified to coherently support the favored choice. Corresponding to the model's simulation, we predicted the direction of such coherence shifts.Cue validities were measured before, after (Exp. 1) and during judgment (Exp. $2 \& 3$ ). Coherence shifts were found in environments involving real-world cue knowledge (weather forecasts) and in a domain for which the application of fast-and-frugal heuristics has been demonstrated (citysize tasks). The results indicate that subjective cue validities are not fixed parameters, but that they are interactively changed to form coherent representations of the task.
\end{abstract}

Keywords: Judgment, Connectionism, Parallel Constraint Satisfaction, Fast-and-Frugal Heuristics, Adaptive Decision Making, Bounded Rationality

PsychInfo Classification Code: (2340) Cognitive Processes

We thank Andrea Ahlgrimm, Susann Fiedler, Stephan Dickert and Christoph Engel for helpful comments on earlier drafts of this article which helped to improve it considerably.

Correspondence concerning this article should be addressed to Andreas Glöckner, Max Planck Institute for Research on Collective Goods, Kurt-Schumacher-Str. 10, D-53113 Bonn, Germany.

E-Mail: gloeckner@coll.mpg.de. 
The only thing we know for sure is that the future is uncertain. This is not to say that chaos rules the world. Some things are quite stable over years and sometimes ages. There are good reasons to assume that ten years from now the sun will rise in the east and a bottle of Coke will contain a beverage that actually tastes like Coke. Conversely, it is hard to forecast next autumn's weather and the quality of a future vintage of German Riesling. In order to cope with uncertainty, organisms can capitalize on probabilistic relations between cues and future events (i.e., between predictors and criteria). In repetitive situations, these relations can be learned by experience. When making a decision, individuals can rely on probabilistic inferences to predict a criterion (e.g., a consequence of a particular kind of behavior) from the presence of a predictor (e.g., a discriminative stimulus). In line with the Brunswikian approach to probabilistic inferences (Brunswik, 1955), the predictor variables are referred to as cues that differ in validity. For choices between two options based on binary cues, the cue validity is defined as the conditional likelihood that options with a positive cue value $\left(c_{+}\right)$are better on the criterion $\left(o_{+}\right)$than options with a negative cue value (in the respective reference class $R): \mathrm{p}\left(o_{+} \mid c_{+}, R\right)$. Objective and subjective cue validities should be differentiated within this approach. The former refer to the relationship between cue and criterion in the environment whereas the latter refer to the interpretation of the validity of the cues by the participants (cue usage, cf. Brunswik, 1955).

Natural environments provide multiple cues for inference. How do people deal with this complexity? Inspired by Herbert Simon's notion of bounded rationality (Simon, 1955, 1982), judgment and decision researchers commonly assume that individuals employ heuristics that reduce complex tasks to simpler ones (see Gigerenzer \& Todd, 1999; Gilovich, Griffin, \& Kahneman, 2002; Kahneman, Slovic, \& Tversky, 1982, for overviews). ${ }^{1}$

It is important to note that there is a difference between (preferential) decisions and judgments (for a historical perspective see Goldstein \& Hogarth, 1997). Decisions can be considered a "commitment to a course of action that is intended to yield results that are satisfying for specified individuals" (Yates, 2003, p. 24; Yates \& Tschirhart, 2006). A judgment, in contrast, is considered "an opinion as to what was, is, or will be the state of some decision-relevant aspect of the world" (Yates \& Tschirhart, 2006, p. 432). In decision research, the term "probabilistic inferences" is used to refer to a special sub-class of judgments in which multiple probabilistic cues are used to determine which of two options is better on a criterion that is not directly accessible (Bröder, 2000; Gigerenzer, Hoffrage, \& Kleinbölting, 1991). In the current work, participants make choices based on probabilistic inferences, such as selecting which of two holiday regions is better with regard to a given weather forecast. As such, we study inferencebased choices rather than preferential decisions.

1 Gigerenzer and Todd (1999) refer directly to Simon's work. It has been argued, however, that the connection between Simon's work and the work by Kahneman, Slovic and Tversky might have been constructed in hindsight (Lopes, 1992). 
A considerable amount of work on probabilistic inferences stems from Gigerenzer and his research group (Gigerenzer et al., 1991; Gigerenzer, Todd, \& ABC Research Group, 1999); they described a couple of fast-and-frugal heuristics in a very precise manner and postulate that individuals learn to apply them adaptively in certain domains. Perhaps the best-known example is the Take the Best (TTB) heuristic. It comprises three steps. First, it selects the cue with the highest subjective validity and looks up the cue values of the alternatives. Second, if one alternative has a higher value than the others, the search for information is stopped (otherwise one goes back to Step 1 and continues one's information search on the second-best cue). The third step contains the decision rule: Predict or choose the winning alternative that is the one with the highest value. Assume you want to decide between two destinations for a holiday based on weather forecasts (cues) only. There are two alternatives on your list, destination $\mathrm{A}$ and destination B. News channels, newspapers, federal and commercial agencies provide a wide variety of cues you can utilize to predict the criterion (weather). Nevertheless, employing TTB makes the task rather easy. You simply look up the prediction from the source you subjectively consider as most reliable, say, the forecast from the biggest news channel in your country. If the cue discriminates between the two destinations (e.g., weather forecaster predicts sunshine for B and rain for A), you base your judgment on this one piece of information and (everything else being equal) make your choice accordingly (e.g., choose B).

The TTB heuristic provides a typical example of the fast-and-frugal heuristics approach: It copes with complexity by using limited information search and hence by ignoring information (Todd \& Gigerenzer, 2003, p. 149). Specifically, it often follows the principle "take the best, ignore the rest" (Gigerenzer \& Goldstein, 1999, p. 81) and is often based on only one reason. Interestingly, probabilistic inferences relying on partial processing of information can yield quite accurate results compared to normative standards as demonstrated by both computer simulations and experimental studies (e.g., Czerlinski, Gigerenzer, \& Goldstein, 1999; Payne, Bettman, \& Johnson, 1988). Proponents of the fast-and-frugal-heuristics approach put forward a number of other simple strategies for probabilistic inference such as the Recognition heuristic (Goldstein \& Gigerenzer, 2002), Quick-Estimation heuristic (Hertwig, Hoffrage, \& Martignon, 1999), Tallying and Minimalist heuristic (Gigerenzer \& Goldstein, 1996). Simplifying rules were also described in the domain of preferential decision making. There is empirical evidence indicating that individuals may apply such strategies as Lexicographic Rule (LEX, Fishburn, 1974), Elimination by Aspects (EBA, Tversky, 1972), Satisficing (SAT, Simon, 1955), the Majority of Confirming Dimensions Rule (Russo \& Dosher, 1983) and the Equal Weight Rule (see Dawes, 1998; Payne, Bettman, \& Johnson, 1988, 1992, for overviews). The mentioned heuristics and strategies differ substantially with regard to their rules for information search, information integration and choice. Despite these differences they share as a common denominator the assumption that information is processed in a unidirectional, non-reciprocal fashion. 
To illustrate this property, again consider the TTB heuristic. Options, cue values and cue validities provide the input for applying the heuristic. Search starts by identifying the cue with the highest validity. Then, the individual compares the values of the options on this cue dimension. If the cue discriminates, the option with the highest value is chosen; otherwise the values on the second cue are inspected. During the application of this heuristic, all of the input-information remains stable. This means, cue validities and cue values are not changed in the course of applying the heuristic. Specifically, there is no backward process included in the building blocks that comprise the strategy. It is uni-directional and non-reciprocal in nature. It feeds in the given information and produces an output by applying rules for search, stopping and choice (the building blocks of the strategy). The same is true for the other strategies mentioned, irrespective of how they operate. Even the most sophisticated tools such as the weighted additive strategy (WADD, which dovetails with the integration rule of expected utility theory) that uses weighting procedures for the given information does not assume reciprocal relations between the parameters. To be sure, any deviation from uni-directionality and input stability would violate the mathematical axioms underlying the WADD model (see Edwards, 1954, for a discussion of such violations in terms of possible interactions of values and weights).

In other words, the described heuristics and strategies converge in assuming that the given information provides the hard constraints under which inference and decision processes evolve. To the best of our knowledge, this basic assumption underlies all of the heuristics that have been so far described as entries to Gigerenzer's adaptive toolbox or to the adaptive decisions maker's repertoire (cf. Payne et al., 1993).

Empirical evidence, however, challenges the notion of uni-directional, non-reciprocal processing. Simon, Krawczyk and Holyoak (2004) measured the subjective importance of outcome dimensions before, during and after decisions were made. Specifically, they presented participants with job offers differing on four dimensions: commute, office size, vacation and salary. The authors provide convincing evidence for coherence shifts showing that subjective weights of the outcome dimensions change in the course of the decision process (see also Simon, Krawczyk, Bleicher, \& Holyoak, 2008). Similar changes were found for the evaluations of arguments in judgments about complex criminal cases (Glöckner \& Engel, 2008; Holyoak \& Simon, 1999; Simon, Pham et al., 2001; Simon, Snow, \& Read, 2004; Simon, 2004). These findings are also in line with other evidence for systematic attribute and cue distortions before and after decisions (Brownstein, Read, \& Simon, 2004; Carlson \& Russo, 2001; Russo, Meloy, \& Medvec, 1998; for an overview see Brownstein, 2003) which operate towards increasing consistency and decreasing dissonance.

Coherence shifts support a constructivist view on judgment and decision making (Holyoak \& Simon, 1999; Montgomery, 1989; Payne, Bettman, \& Johnson, 1992; Pennington \& Hastie, 1992; see also Slovic, 1995). Accordingly, decision makers seem to actively change the given information (e.g., cue validities; importance of information) in order to accentuate differences 
between the options, to increase dominance and to form a coherent impression of the problem at stake. These constructive properties of decision making can be easily accounted for in a connectionist approach (Betsch, 2005; Glöckner, 2006; 2007; Glöckner \& Betsch, 2008c; Holyoak \& Simon, 1999; Read, Vanman, \& Miller, 1997; Thagard \& Millgram, 1995). Connectionist models conceive judgment and decision making as a holistic process characterized by an automatic, parallel consideration of multiple pieces of information which are integrated based on consistency-maximizing processes. On a general level, connectionist models make the prediction that the cognitive processes underling decision making are multi-directional and reciprocal. As such, an evaluation of a cue not only impacts the evaluation of a criterion, but the evaluation of the criterion also affects the evaluation of the cue. Moreover, the recursive relation between the cue and the criterion is itself a function of all the other pieces considered. This constructivist notion significantly deviates from the view of uni-directional and non-reciprocal reasoning that underlies the conception of a wide range of heuristics and strategies.

Beyond this general prediction, connectionist models of judgment and decision making can also predict the conditions, the direction and the size of changes made to the information given. By applying a Parallel Constraint Satisfaction (PCS) model (Glöckner \& Betsch, 2008c) we will test to what extent observed changes to the input information converge with the changes predicted by the model's simulation.

The present research pursued two goals. First, we aimed at testing the generality of previous findings. Prior empirical work from the domain of legal judgment shows that constructive coherence shifts occurred in multi-attribute outcome-based decisions (Pennington \& Hastie, 1992; Simon, 2004). The present research explores whether similar findings can be obtained in such simple probabilistic inference tasks that have been widely used to identify fast-andfrugal heuristics such as the TTB heuristic. Specifically, we investigated the stability and change of subjective cue validities during probabilistic inference tasks on (a) choosing a holiday destination upon inspection of well-known weather forecasts and (b) selecting the larger city based on different cues (Gigerenzer \& Goldstein, 1996).

The second goal was to further evaluate the validity of our PCS approach to judgment and decision making. To this end, we compare the size and direction of individuals' coherence shifts with predictions derived from model simulations.

\section{A PCS Approach to Probabilistic Inferences}

The model described below builds on a number of different approaches to judgment and decision making. Similar to the dominance-structuring model (Montgomery, 1989) and the differentiation and consolidation model (Svenson, 1992), it draws on the assumption that (re)structuring of information is an integral part of the judgment and decision process. PCS is 
based on principles of perception (McClelland \& Rumelhart, 1981; Read \& Miller, 1998), which have been emphasized as an important framework for future research in judgment and decision making (Maule, 2005). Therefore it is a plausible mechanism from an evolutionary perspective (cf. Gilbert, 1991), which might account for the automatic processes in decision making that have been highlighted by several authors (Dougherty, Gettys, \& Ogden, 1999; Holyoak \& Simon, 1999; Kahneman \& Frederick, 2002; Montgomery, 1989; Weber, Goldstein, \& Barlas, 1995).

The PCS approach postulates that consistency maximizing processes, which can be simulated by connectionist networks, are one of the core operating processes of judgment and decision making (Glöckner \& Betsch, 2008c; Holyoak \& Simon, 1999; Simon, 2004). It has been argued that individuals use these Gestalt-like processes to form consistent interpretations of the task. Dependent on the structure of the task, advantages of one or the other interpretation (i.e. option) are automatically accentuated and enter awareness. The resulting (more or less conscious) mental representations are the basis for judgments and decisions. The option with the highest activation within this mental representation is chosen. Glöckner and Betsch (2008c) have argued that in the case that the mental representation does not reach an aspired level of consistency, deliberate processes are additionally activated to support consistency maximizing in the network. In the following, for simplicity, we will focus only on the part of the model which describes the automatic consistency maximizing processes (i.e., the primary network; Glöckner \& Betsch, 2008c).

In order to model simple probabilistic inference tasks, Glöckner and Betsch (2008c) adopted the general connectionist approach proposed for preferential and complex legal decision making. Thereby, the degrees of freedom in the model were reduced by specifying the structure of the network. As depicted in Figure 1, the first set of units represents options, the second set represents cues, and a special unit represents the general concept of validity of information. The links between options and cues reflect cue information (e.g., that cues speak for or against options). The links between the general validity node and the cues reflect the initial subjective cue validities (which could be based on learning experiences). Using a parallel constraint satisfaction algorithm (McClelland \& Rumelhart, 1981; Read, Vanman, \& Miller, 1997), activations of the nodes are changed to reach a consistent solution (activation pattern) that satisfies the constraints in the system (fixed links and weights). ${ }^{2}$ The final activation of

2 The iterative updating algorithm uses a sigmoid activation function proposed by McClelland and Rumelhart (1981; see also Read and Miller, 1998):

$$
\begin{aligned}
& a_{i}(t+1)=a_{i}(t) *(1-\text { decay })+\left\{\begin{array}{ccc}
\text { if } & \text { input }_{i}<0 & \text { input }_{i} *\left(a_{i}(t)-\text { floor }\right) \\
\text { if } & \text { input }_{i} \geq 0 & \text { input }_{i} *\left(\text { ceiling }_{-} a_{i}(t)\right)
\end{array}\right. \\
& \text { input }_{i}(t)=\sum_{j=1 \rightarrow n} w_{i j} * a_{j}(t)
\end{aligned}
$$

$a_{i}(t)$ represents the activation of the node $i$ at iteration $t$. The parameters floor and ceiling stand for the minimum and maximum possible activation (in our model set to a constant value of -1 and +1 ). Input $(t)$ is the activation node $i$ receives at iteration $t$, which is computed by summing up all products of activations and connection weights $\mathrm{w}_{\mathrm{ij}}$ for node $\mathrm{i}$. Decay is a constant decay parameter. 
the option nodes indicates the valence of the options, whereas the final activation of the cue nodes represents posterior subjective cue validities (i.e., the subjective validity of the cue after constraint satisfaction). The number of iterations of the relaxation algorithm to form the coherent pattern of activations can be used as an estimate for the expected decision time for the model. ${ }^{3}$ ote that PCS networks take the network structure as given and simulate only the current interpretation given this evidence structure (Shultz \& Lepper, 1996). Changes in the structure of the network (i.e., in the link weights) that might be caused by long-term learning (supervised or unsupervised) are not part of model. Hence, PCS models are in almost all respects different from simple connectionist models which have already been tested against fast-and-frugal heuristics (Rieskamp, 2006).

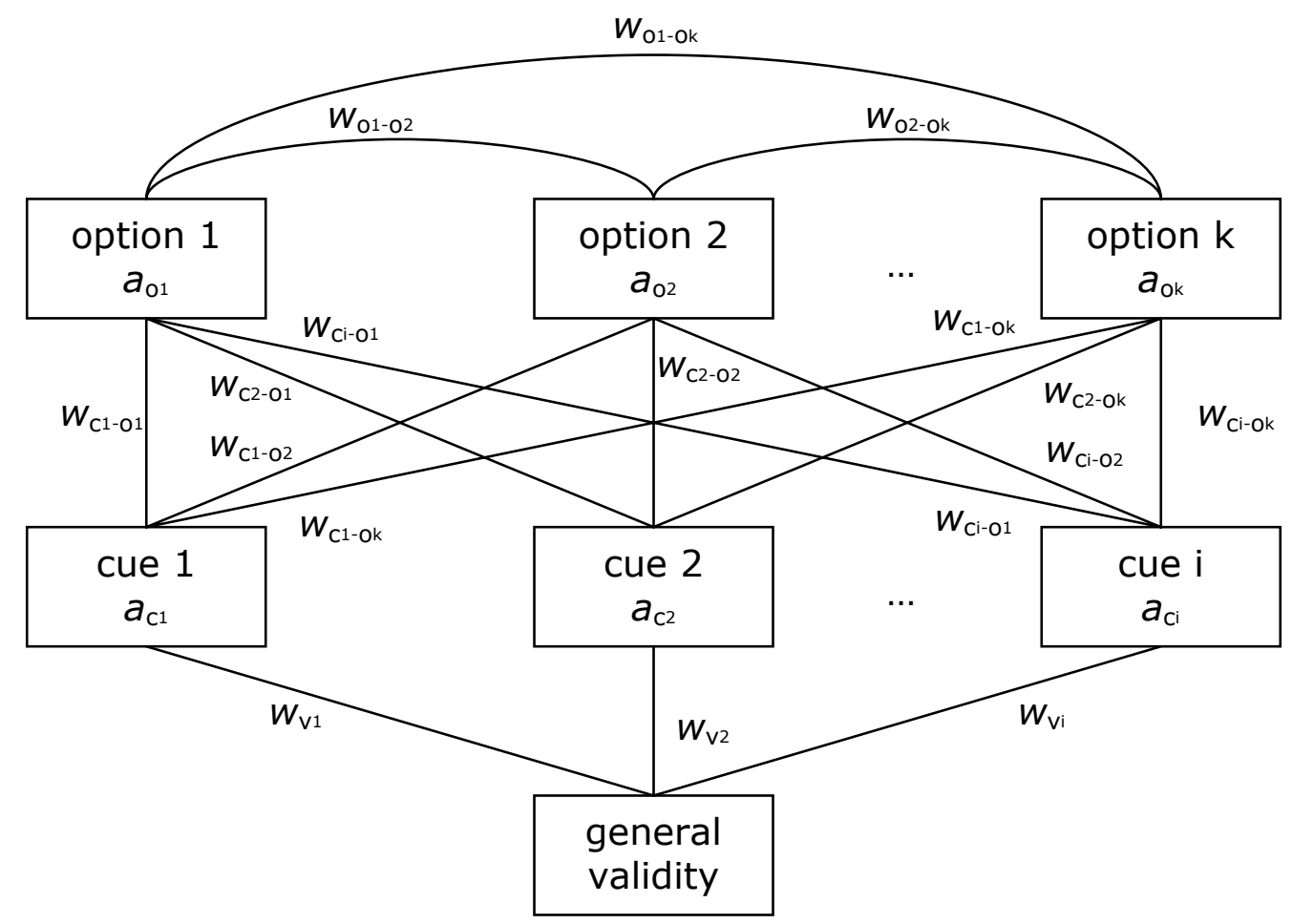

Figure 1. The general model for probabilistic inferences is depicted. Boxes represent nodes; lines represent links, which are all bi-directional. Connection weights can range from -1 to +1 and are labeled $w$. Using the iterative updating algorithm coherence is produced in the network by changing activations $a$. The special node general validity has a constant activation of +1 and is used to supply the network with energy.

Systematic changes in evaluations of attributes or subjective cue validities are by-products of the PCS process. Thus, from the general PCS approach it can be predicted that in probabilistic inference tasks the subjective validity of cues supporting the favored option is increased

3 The proposed PCS model shares some structural similarities with recent formulation of decision field theory (Busemeyer \& Townsend, 1993; Busemeyer \& Johnson, 2004) and other evidence accumulation models (Usher \& McClelland, 2001, 2004). ue to the assumption of unidirectional connections, however, these theories would not predict changes in subjective cue validities. 
whereas the subjective validity of conflicting cues is decreased. We ran several simulations of the network model described above which indicate that such a prediction can indeed be derived from the specific model. The findings are robust against variations of parameters (e.g., decay rates, connection weights). The simulations used a probabilistic inference task in which the most valid cue predicts option $A$ and all the remaining cues predict option B. The simulation results demonstrate that the subjective validity of the most valid cue decreases systematically in such a cue constellation but only if the other cues overrule the most valid cue (i.e., option B is chosen). In contrast, a substantial increase in the validity of the most valid was observed in the alternative case (i.e., option A is chosen).

In the experiments, we used probabilistic inference tasks with several valid cues and a high number of cues pointing against the most valid cue. According to the PCS rule, this should lead to more homogeneous judgments and, thus, should reduce the likelihood for zero effects caused by aggregating heterogeneous coherence shifts. Furthermore, only relatively valid cues were chosen to assure low differences between the cue validities. ${ }^{4}$

In the first experiment, we tested whether changes in subjective cue validities also occur for cues for which participants have some experience, namely for prominent weather forecasts. Students can hardly avoid recognizing (at least occasionally) weather forecasts in TV channels, newspapers and the internet and they certainly cannot avoid experiencing the weather on their way to university. Hence, for average German students a sufficient number of (at least implicit) learning trials can be expected for some of the prominent German weather forecasts used in the experiment.

\section{Experiment 1: Coherence Shifts for Weather-Forecasts}

Participants had to choose between two destinations for a holiday based on weather forecasts (cues) from different prominent sources. The subjective validity of the cues was measured before and after the choice. Based on the results of the simulations, we predicted that cue validities are changed to form a consistent representation of the task. In detail, we hypothesized that the subjective validity of one highly valid cue conflicting with the majority of other valid cues should decrease and the validity of the other cues should increase. Additionally, we considered strategy application by analyzing individuals' choice behavior. Although strategy choice is not the primary focus of this research, we consider choice behavior for two reasons. First, it provides another test of the PCS model's predictions. Second, it allows us to test whether our prior findings can be replicated. Specifically, we found that individuals predomi-

4 The selection of relatively valid cues might give a slight advantage to compensatory strategies (e.g., equal weight rule, WADD, PCS) in contrast to non-compensatory ones (e.g., TTB) in that the ignorance of less valid cues leads to a larger information loss (but see Exp. 3). Note, however, that this aspect of the experimental environment is irrelevant for testing our hypothesis concerning the dynamic change of cue validities. It would be only of importance if we wished to test the prevalence of certain strategies - which is not the focus of the paper. 
nantly process information in a compensatory, holistic fashion instead of relying only on a subset of the given information (e.g., Glöckner \& Betsch, 2008a, 2008c).

\section{Method}

Participants and design. Participants were 74 students (60 female; mean age 21) from different majors at the University of Erfurt, who took part in a one-hour experimental battery and were rewarded with 6.00 Euro for their participation. They were randomly assigned to two between-subjects conditions in which cue values were manipulated (cue values). Each participant rated the subjective validity of four cues (cue) before and after the choice (time). This resulted in a 2 (cue values) x 4 (cue) x 2 (time) mixed model design with the two latter variables being within-subject factors.

Procedure. The experiment was entirely computer-directed and consisted of three parts. The complete instruction can be found in the appendix. In the first part, we measured subjective cue validities by asking for subjective cue usage (Brunswik, 1955). Specifically, participants indicated how much they would rely on several well-known sources for 7-day-ahead weather forecasts using a horizontal scroll bar ranging from -100 (not rely at all) to +100 (rely completely). The sources, which will be called cue 1 to cue 4, were two TV stations, one newspaper, and one Internet source. ${ }^{5}$ In the second part, lasting about 30 minutes, participants worked on a few unrelated tasks. In the third part, participants were to select the destination with the lower probability of rain based on these weather forecasts. Thereby, we used a coverstory in which decisions between two holiday destinations A and B based on different 7-dayahead weather forecasts were made. After the decision, we had participants rate the subjective validity of the sources of weather forecast using the same measure as in part 1.

The cue values were manipulated between participants to rule out that changes in subjective validities might depend on effects of repeated measurement only. In condition 1 , cue 2 predicted rain for destination $\mathrm{A}$ and sun for destination $\mathrm{B}$ and all other cues predicted the reverse pattern. In condition 2, cue 1 predicted rain for destination A und sun for destination B and all other cues predicted the reverse pattern. Thus, according to the PCS model, in both conditions most people should choose destination B. But whereas in condition 1 the validity of cue 2 should decrease, in condition 2 a decrease in the validity of cue 1 was expected. At the same time, in both conditions, all other subjective cue validities should increase from pre- to posttest. In contrast, if individuals would apply a one-reason decision strategy such as TTB, they should choose destination A or B, depending on the prediction of the most valid cue only. As mentioned above, application of any of the simple and complex heuristics/strategies described in the introduction should not result in changes to cue validities. 


\section{Results}

Analysis of the choices revealed that almost all of the participants chose destination B (condition $1=90 \%$, condition $2=100 \%$ ) as predicted by the PCS rule (under the assumption that the three cues taken together are stronger than the one very valid but diverging cue). According to the subjective cue validity rating in the pre-test, for 23 participants the cue predicting against the majority of cues was initially rated the most valid cue. Twenty-one of these participants (91.3\%) chose destination B, although the most valid cue made a prediction for destination A. For these participants it can be ruled out that they did apply TTB. Note, however, that besides PCS also other models like equal weighting rule or WADD could account for participants' choice behavior (but see coherence shift results below).

A 2 (cue values) x 4 (cue) x 2 (time) mixed-model analysis of variance (ANOVA) with time and cue as within-subjects factors and the validity ratings as dependent variables revealed significant main effects for cue, $F(2.3,164.5)^{6}=106.2, p<.001, \eta^{2}=.60$; and for time, $F(1,72)$ $=4.13, p<.05, \eta^{2}=.05$. The main effect of cue was driven by considerable differences in the subjective validity between cues. The differences could be attributed to systematically different learning experiences concerning these natural cues. Means of subjective validities (with standard error in parentheses) for cues 1 to 4 were 53.4 (2.1), 73.6 (1.9), 27.4 (2.4), 71.9 (2.5). The main effect for time was caused by the higher general ratings in the post-test (Figure 2).

6 A Greenhouse Geisser correction was used because Mauchly's test of sphericity turned out to be significant. The same correction was applied to all further repeated measurement analyses, if the assumption of sphericity was violated. 


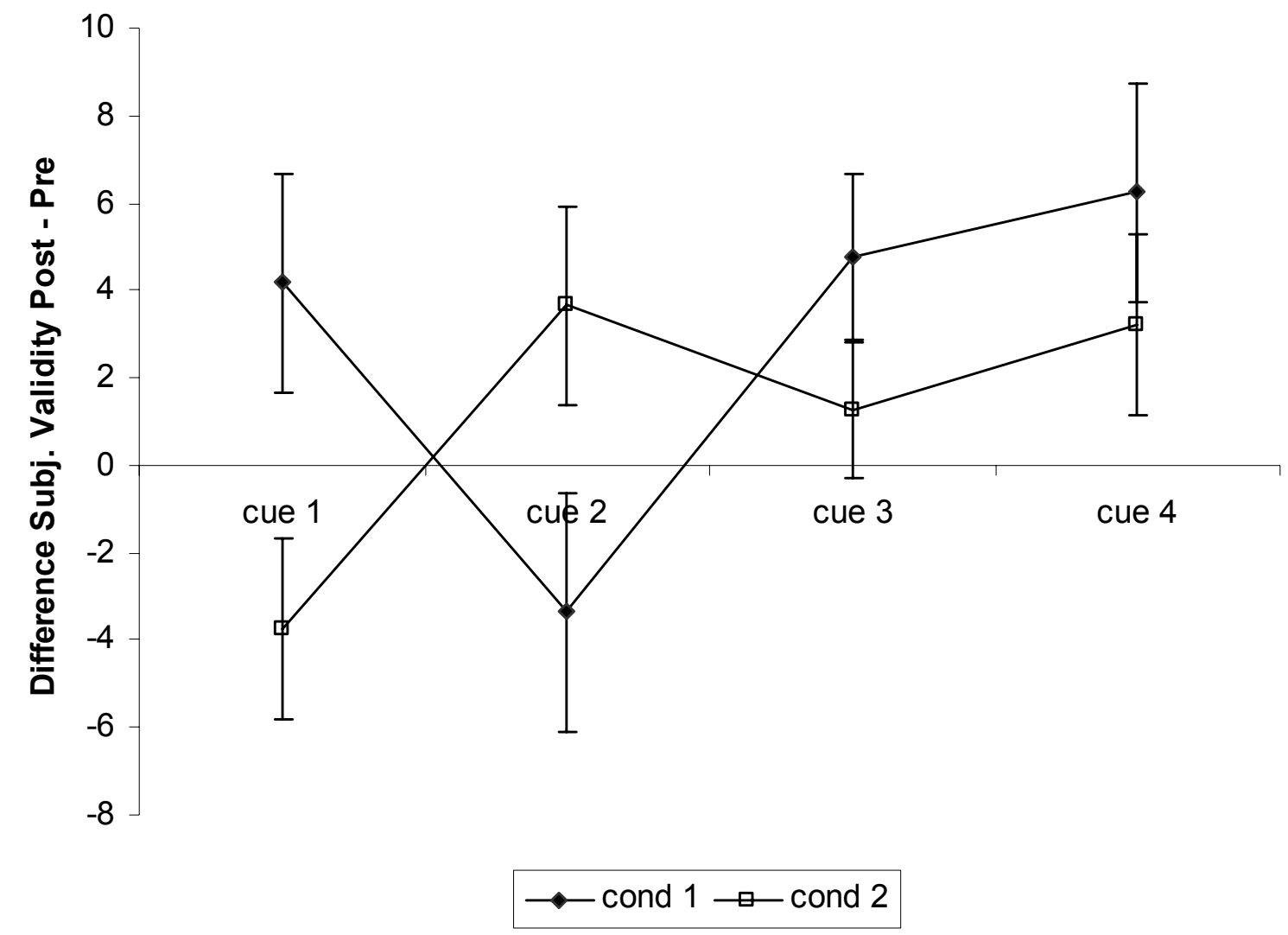

Figure 2. The results of Experiment 1 are presented using difference scores between judgments of the cue validity post-test minus pre-test, positive numbers standing for an increase in subjective validity judgment. Error bars represent the SE for difference scores.

More interestingly and in accordance with our hypothesis, the three-way interaction of cue values, time and cue turned out to be significant, $F(2.7,194.6)=5.0, p<.01, \eta^{2}=.07$. Inspection of Figure 2 shows that all changes in subjective cue validity were in the predicted directions: in condition 1, the subjective validity was reduced for cue 2 and increased for all other cues, and in condition 2, a decrease for cue 1 and an increase for all other cues was observed.

\section{Simulation}

To test how well the PCS model predicts choices and coherence shifts, we ran individual simulations for each participant. An optimal model fit can, of course, be reached by fitting several model parameters to the data of each individual. However, due to the limited number of data points we refrained from doing so and simply used one set of parameters that had been proved to be reasonable in previous studies. We used the same set of parameters for all individuals and also for the later reported studies being aware of the fact that the model fit is thereby somewhat underestimated. The parameter values we used are summarized in Table 1 
and the influence of parameters on predicted results are sketched (for a description of the parameters, see also Figure 1 and Footnote 2).

Table 1: Model Parameters for PCS Simulations

\begin{tabular}{|c|c|c|}
\hline & $\begin{array}{l}\text { Value / } \\
\text { Function }\end{array}$ & Comment \\
\hline Decay & .05 & $\begin{array}{l}\text { Decay parameter for node activation; influences the overall activation } \\
\text { level of the nodes, the higher the value the lower the final activation level. }\end{array}$ \\
\hline$w_{01-02}$ & -.20 & $\begin{array}{l}\text { Inhibitory connection between options; influences the size of coherence } \\
\text { shifts; the stronger the inhibitory connection the stronger the coherence } \\
\text { shifts. }\end{array}$ \\
\hline$w_{\mathrm{c}-\mathrm{o}}$ & $.01 /-.01$ & $\begin{array}{l}\text { Connection between cues and options representing positive or negative } \\
\text { predictions. }\end{array}$ \\
\hline$w_{\mathrm{v}}$ & $w=(v / 200)^{2}$ & $\begin{array}{l}\text { Links between general validity node and cues representing a priori cue } \\
\text { validity. The transformation function should depend on the scale values } \\
\text { and labels used for measuring the a priori validity } v \text {. Link weights in the } \\
\text { range of } 0 \text { to } 0.25 \text { have been found to be useful. We divide the a priori } \\
\text { cue validities } v \text { by } 200 \text { and take the result to the power of } 2 \text {. (For individ- } \\
\text { ual' level data fitting the exponent could be potentially used as one free } \\
\text { parameter). }\end{array}$ \\
\hline $\begin{array}{l}\text { ceiling / } \\
\text { floor }\end{array}$ & $1 /-1$ & Upper and lower limit for cue activations. \\
\hline
\end{tabular}

The results of the simulation were nicely in line with the observed data. Choices were almost perfectly predicted by the model and the predictions for posterior cue validities (i.e., final activations of the cue nodes after finding a stable solution) correlated highly with the observed ratings of cue validities in the post-test (Table 2). 


\begin{tabular}{|c|c|c|c|}
\hline & Exp. 1 & Exp. 2 & Exp. 3 \\
\hline \multicolumn{4}{|c|}{ Correlations PCS Cue-Validity Predictions and Data } \\
\hline Cue 1 & $.72^{* * *}$ & $.51^{* * *}$ & $.66^{\star * *}$ \\
\hline Cue 2 & $.61^{* * *}$ & $.45^{* * *}$ & $.74^{* * *}$ \\
\hline Cue 3 & $.87^{* \star *}$ & $.53^{* * *}$ & $.71^{* * *}$ \\
\hline Cue 4 & $.71^{* * *}$ & $.56^{* * *}$ & $.83^{* * *}$ \\
\hline \multicolumn{4}{|c|}{ PCS Choice Predictions } \\
\hline Correct & $96 \%$ & (not available) & $75 \%$ \\
\hline Observations & 74 & 65 & 60 \\
\hline
\end{tabular}

To investigate in more detail whether the PCS model predicts cue validity ratings in the posttest better than other model that assume stable cue validities, we conducted regressions in which we predicted the post-test ratings from a) only the PCS prediction (i.e., posterior cue activation), b) controlling for the a priori rating of cue validity in the pre-test, and c) additionally controlling for condition and differences in the re-valuations of (dummy coded) cues (Table 3). We found that PCS simulation results contributed significantly to the prediction of the post-test ratings in all three regressions. This indicates that PCS accounts for validity ratings very well and the significant effect when controlling for pre-test ratings demonstrates that the model predicts better than heuristics and other models that assume stable cue validities. 
Table 3: Regression Predicting Cue Ratings in the Post-Test

\begin{tabular}{lccc}
\hline & $(1)$ & $(2)$ & $(3)$ \\
& Post-Rating Cue & Post-Rating Cue & Post-Rating Cue \\
\hline PCS-Prediction & $96.29^{* *}$ & $11.47^{+}$ & 17.15 \\
& $(16.85)$ & $(1.79)$ & $(2.47)$ \\
Pre-Rating Cue & & $0.787^{*+*}$ & $0.629^{*+*}$ \\
& & $(11.88)$ & $(6.52)$ \\
Condition 2 & & -0.0370 \\
(0=no, 1=yes) & & $(-0.02)$ \\
Cue 2 & & $6.707^{* *}$ \\
(0=no, 1=yes) & & $(3.00)$ \\
Cue 3 & & & -3.279 \\
(0=no, 1=yes) & & $(-1.38)$ \\
Cue 4 & & & $9.442^{* * *}$ \\
(0=no, 1=yes) & & & $(4.16)$ \\
Constant & & & 6.145 \\
& & & $(1.63)$ \\
\hline$N$ & $-16.83^{* * *}$ & $4.883^{+}$ & 296 \\
\hline
\end{tabular}

Note. To account for the repeated measurement design SEs were adjusted for 74 clusters of observations and robust standard errors were used to account for violations of the homoscedasticity assumption (Gould, Pitblado, \& Sribney, 2006; Hayes \& Cai, 2007). The $t$ statistics are presented in parentheses. Significance levels are indicated by ${ }^{+} p<0.10,{ }^{*} p<0.05,{ }^{* *} p<0.01$, and ${ }^{* * *} p<0.001$.

Further exploratory simulations showed the robustness of the predictions against changes in parameters (i.e., decay, negative connection between options) and indicated that the prediction could further be improved using somewhat different parameter values.

\section{Discussion}

The results corroborate the assumption that subjective cue validities are changed to form a consistent representation of a probabilistic inference task. As such, the present research further substantiates the validity of similar findings obtained earlier (e.g., Simon et al., 2004) and shows that they also apply to the probabilistic inference tasks. Moreover, the results concerning coherence shifts are nicely in line with the specific PCS-predictions when modeling individuals' choices. Thus the PCS model proved to provide a useful theoretical framework to account for the direction of changes and the dynamics underlying constructive, holistic processing in decision making.

The PCS model predicts that information is holistically considered with the goal to find a solution to the task that coheres best with all the other pieces of information. To work out a co- 
herent solution, the information is processed in a reciprocal, multidirectional and constructive fashion. Specifically, the relative impact is enhanced for those pieces of information that already cohere and the relative impact is attenuated for conflicting information. In a connectionist metaphor, this is achieved by changing activation of nodes in a working network representing the decision task at stake. In the present task, the predictions of three cues converged, but were in opposition the prediction of the most valid cue. For this kind of information structure, the PCS model predicts that the impact of the most valid cue will be attenuated, whereas the impact of the others will be inflated. These changes should manifest themselves in a decrease in subjective validity of the most valid cue and an increase in subjective validity of the others. This predicted direction of changes was strongly corroborated by the evidence resulting from a comparison of pre- and post measures of subjective cue validity.

Choice behavior was also in line with predictions derived from simulations of the PCS model. Moreover, choices indicated that individuals processed all pieces information in a compensatory manner rather than relying on the most valid cue only.

As a caveat to the present study, we have to acknowledge that the second measure of cue validities was applied after and not during the decision process. Thus, we cannot rule out that subjective cue validities were not changed during the process of making a probabilistic inference, but after the choice was made. Dissonance theory predicts that many (but not all) decisions cause cognitive dissonance (Festinger, 1964). To achieve cognitive consistency, individuals tend to change the evaluation of alternatives after a decision which leads to a spreading-apart effect. Accordingly, the chosen alternative is rated more favorably, and the rejected alternatives are rated more negatively. Note, however, that it is unclear if cognitive dissonance generalizes to judgment and choices based on probabilistic inferences.

Nevertheless, at the moment we cannot rule out an alternative interpretation of the results in terms of post-decisional dissonance reduction (but see Exp. 2). However, even such an interpretation has some important theoretical implications. As a common denominator, dissonance theory and the connectionist approach share the assumption that individuals strive for consistency or coherence (see also Egan, Santos, \& Bloom, 2007). Not surprisingly, parallel constraint satisfaction models have been used to model dissonance reduction (Shultz \& Lepper, 1996). Most notably, the notion of cognitive consistency implies that our mind processes information in a holistic, interactive fashion. Information units mutually influence each other and thus cannot be considered in isolation. This view differs markedly from the notion underlying the heuristics and strategies described earlier. ${ }^{7}$

7 Note that the cue distribution in our study would allow for application of the TTB heuristics because there was one dominant cue available that effectively discriminated between alternatives. Interestingly, application of the TTB heuristic would not have caused cognitive dissonance to arise in the present task. TTB requires only consideration of one cue. If a person considers, say, cue 2 as the cue with highest validity and the forecast predicts fine weather in destination A and bad weather in destination B, then she can immediately select destination A. The chosen option has only positive outcomes (fine weather) and the option 


\section{Experiment 2: Coherence Shifts without Commitment to an Option}

To further substantiate the hypothesis that coherence shifts occur during the judgment, we conducted a second experiment. Materials and procedures were the same as in Experiment 1, with the exception that the choice measure was removed. We tested the prediction that people change subjective cue validities upon perceiving and thinking about the situation even without committing themselves to a certain option (cf. Simon et al., 2001). Note that dissonance theory predicts the absence of dissonance reduction processes under these conditions: "We must accept the fact that dissonance-reduction processes do not automatically start when a decision is made... The decision must have the effect of committing the person." (Festinger, 1964, p. 42).

\section{Method}

Participants and design. Sixty-five students of the University of Erfurt (60 female; mean age 20 years) participated in the experiment, which was run as part of a one-hour experimental battery. Students received 6.00 Euro for their participation. No between-subject manipulation was used. Subjective cue validities of four cues were again measured in a pre- and a post-test resulting in a 4 (cue) x 2 (time) within-subjects design.

Procedure. Procedure and materials were the same as in condition 1 of the previous study, with the exception that the actual choice was removed. First participants judged the subjective validity of the cues. After a 30-minute distraction phase they could inspect weather forecasts and were asked to think about a possible solution of the task. However, they were instructed not to make a final choice. Subsequently, participants were asked to judge the subjective validity of the cues again. The exact modifications of the instruction compared to Experiment 1 can again be found in the appendix.

\section{Results}

A 4 (cue) x 2 (time) repeated measurement ANOVA with time and cue as within-subjects factors and the subjective cue validity as the dependent variable was used to analyze the data. The analysis revealed a significant interaction of cue and time, $F(1.9,123.6)=7.5, p=.001$, $\eta^{2}=.11$. The significant main effect for cue was replicated, $F(2.2,141.5)=67.7, p<.001, \eta^{2}$ $=.51$. Inspection of Figure 3 shows that the results of the present and the previous experiment

not chosen has only negative outcomes (bad weather). Under such conditions, dissonance theory predicts the absence of a spreading-apart effect, simply because no positive information about the non-chosen alternative is considered (cf. Frey, 1981, for an insightful discussion). 
converge. As expected, the subjective validity of cue 2 was decreased and the subjective validity of the other cues was increased by merely reflecting on the decision task.

\section{Discussion}

The second study shows that shifts in subjective cue validities can occur even before an explicit judgment or decision is made and before a person is committed to an option. It rules out alternative interpretations in terms of post-decisional dissonance reduction and provides further support for a connectionist approach to probabilistic inferences.

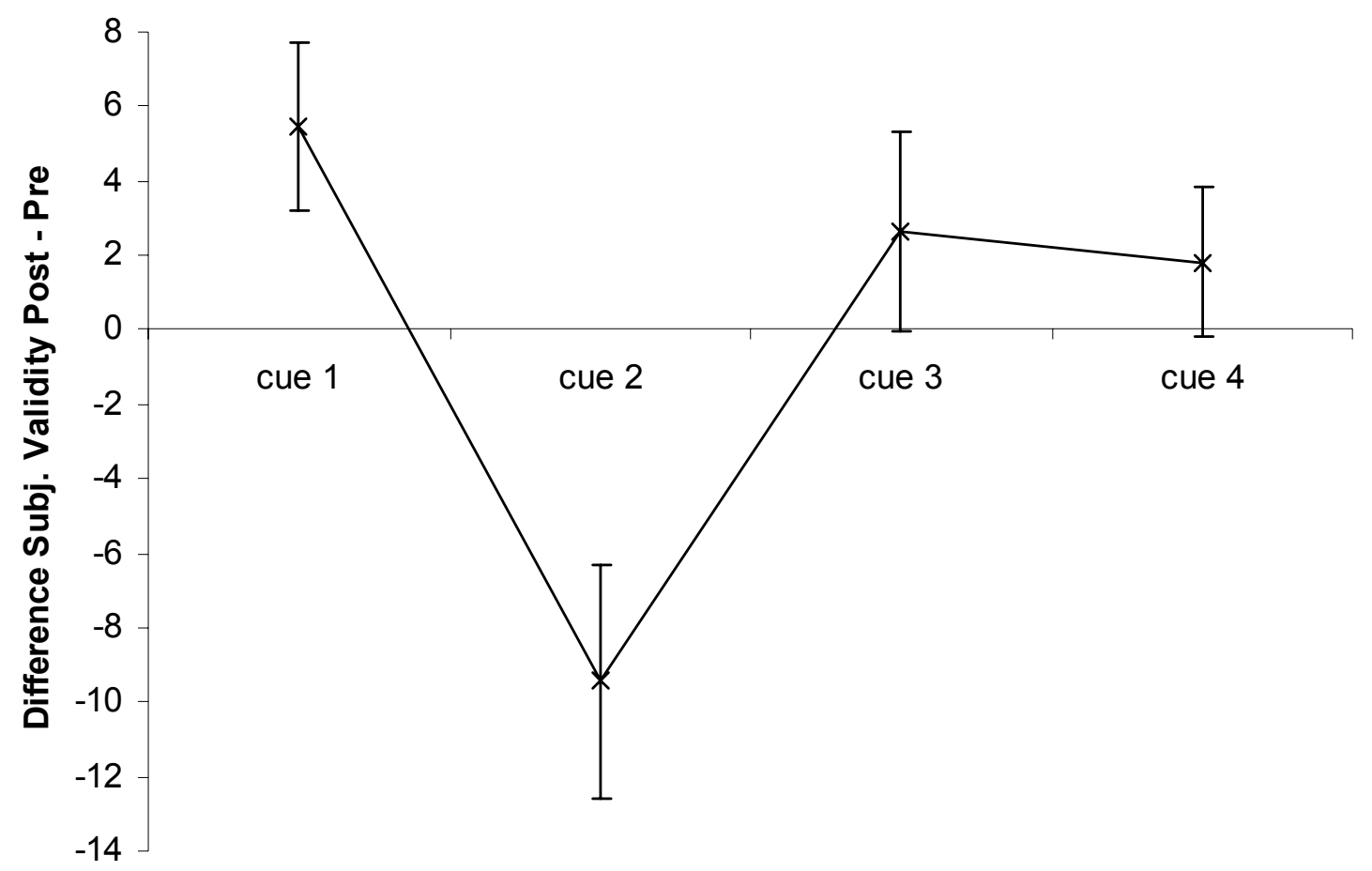

Figure 3. The results of Experiment 2 are presented using the same difference scores as in Figure 2. Error bars represent the SE for difference scores.

To test whether the observed coherence shifts can be predicted by the PCS model, we again run simulations on individual data to predict posterior cue validities based on a posteriori activation of cue nodes. In the simulation, we used the same parameters as in the simulation of the previous study (see Table 1). Again the cue validity ratings in the post test were very well predicted by the model as indicated by highly significant correlations for all four cues (see Table 2).

As a second caveat, one might criticize our measurement method for the dependent variable subjective cue validity. In line with the classic Brunswikian approach, participants rated subjective cue validities by estimating their personal cue utilization (i.e., relation between cues 
and individual / right side of the lens model). Alternatively, it might be possible to measure subjective cue validities by asking participants about their beliefs concerning the objective cue validities (i.e. the relation between cue and criterion / left side of the lens model).

We argue that in order to evaluate descriptive models for probabilistic inferences, it might be more appropriate to ask for estimations of cue utilization (used in Exp. 1 \& 2) than for estimations of the objective cue validity (i.e., beliefs; see Exp. 3). The former aim to measure influences on judgments directly, whereas the latter are cognition which could affect judgments but in a not exactly specified way. However, findings on failures of introspection (Nisbett \& Wilson, 1977) speak against the reliability of explicit ratings of cue utilization. Fortunately, according to the finding that coherence shifts also change background knowledge (Simon, 2004), substantial but probably smaller coherence shifts can be expected for subjective ratings of objective cue validities (i.e., beliefs) as well.

We aimed to rule out this objection empirically by conducting a third experiment. In contrast to the prior studies, we measured subjective cue validities by assessing participants' beliefs about the environment (i.e., conditional likelihoods) instead of ratings of cue usage. We also changed the task to test whether the findings obtained so far would generalize to other domains of probabilistic inference. Specifically, we employed the city-size task which has been frequently applied in research on the fast-and-frugal heuristics approach (Gigerenzer et al., 1999). In the city-size task, individuals have to select the larger of two cities based on different cues (e.g., the city is / is not a state capital). The city-size task has been used to provide existence proofs for the application of the TTB heuristics (e.g., Gigerenzer \& Goldstein, 1996). Hence, the third experiment also provides another test of the prevalence of the TTB heuristic in particular and the application of non-compensatory and simple (one-reason) heuristics in general. Note that our PCS model predicts that all of the given information is processed in a holistic and compensatory fashion.

\section{Experiment 3: Coherence Shifts in the City-Size Task}

\section{Method}

Participants and design. Sixty-three students of the University of Erfurt (55 female; mean age 20.8 years) participated in the experiment, which was run as part of a 45 -minute experimental battery. Students received 5.00 Euro for their participation. Four cue validities were measured in pre- and post-tests resulting in a 4 (cue) x 2 (time) repeated measurement design.

Procedure. In the experiment, individuals had to think about which of two cities is larger, based on the following cues: the city is or is not a state capital; the city has or does not have a university, an international airport and/or a premier league soccer team (the "1. Bundesliga" in our German version of the task). As in the previous experiment, participants did not make 
any explicit judgment or choice in the first part to avoid post-decisional dissonance effects. At the beginning, the definition of cue validity based on conditional likelihood was carefully explained to the participants. They were instructed to estimate the validity of the four cues on a scale from $0 \%$ to $100 \%$ using a horizontal scroll bar. After a filler-task of approximately 15 minutes, the participants were presented with a probabilistic inference task which was structurally the same as the tasks in the previous experiments. The most valid cue (state capital) pointed against all lower cues. Participants should imagine participating in a quiz show where they have to judge which of two cities is larger without exact knowledge about the cities' populations. They were told that city $\mathrm{A}$ is a state capital but has no university, no international airport, and no premier league soccer team, whereas city B is not a state capital but has a university, an international airport, and a soccer team in the premier league. Participants were instructed not to make a judgment yet, because the quizmaster would soon provide additional important information, but that they should try to understand the information set. Then the cue validity was measured using the same method as in the pre-test. In the second part of the study, participants were informed that the quizmaster was not allowed to give the additional information, and that they had to make a choice without it (i.e., they were to decide which of the two cities is larger). The complete instruction is provided in the appendix.

\section{Results}

Exploratory analyses revealed that three participants repeatedly produced extreme outliers $(M$ $+/-3 S D$ ) for the difference between cue validity ratings from pre- to post-test. These three persons were excluded from the analysis. Again, a repeated measurement ANOVA with time and cue as within-subjects factors and subjective cue validity as the dependent variable was computed to analyze the data. It indicated a significant interaction of cue and time, $F(2.7$, $158.3)=3.1, p=.03, \eta^{2}=.05$. In line with the predictions of the PCS model and the findings of experiments 1 and 2, working on the probabilistic inference task systematically influenced the ratings of cue validity (Figure 4). The subjective validity of the most valid cue "state capital" was substantially decreased. In contrast to the previously reported studies, we did not find a substantial increase in the validities of the other cues. However, the subjective validities of two of the three cues were at least modified in the expected direction. The size of the coherence shifts decreased when estimations of objective cue validities were used as dependent measures. The reduced effect can be explained by the fact that estimation of objective cue validities might be only a kind of background knowledge to the judgment and therefore might only be indirectly influenced. 


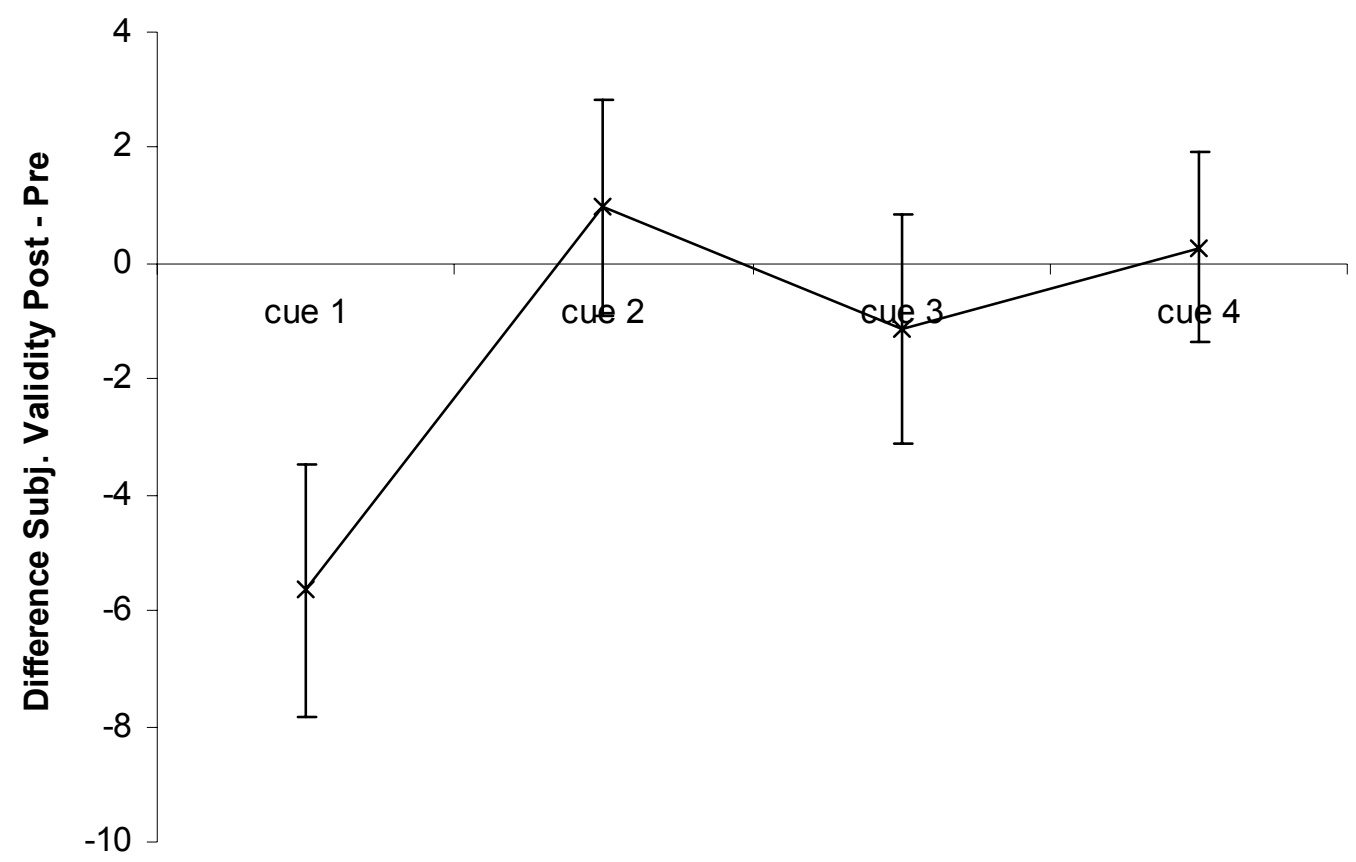

Figure 4. The results of Experiment 3 are presented using the same difference scores as in Figure 2. Error bars represent the $S E$ for difference scores.

A significant main effect for cue was found, $F(2.7,158.6)=27.3, p<.001, \eta^{2}=.32$. The average cue validity ratings for the cues international airport, state capital, university, and soccer team (with $S E$ in parentheses) were 74.6 (2.85), 73.7 (2.54), 59.1 (2.59), and 48.5 (3.18). As intended by the selection of the cues, state capital was considered the most valid cue in the pre-test. In the post-test, however, the international airport was considered the most valid cue, indicating that consistency maximizing processes do not only account for minor changes of validity ratings but can even lead to alterations in the ordinal cue hierarchy (state capital: $M_{\text {pre }}=76.5, S E=2.8$ vs. $M_{\text {post }}=70.9, S E=2.7$; Airport: $M_{\text {pre }}=75.2, S E=3.2$ vs. $M_{\text {post }}=74.1$, $S E=2.8)$.

Analyses of the choices showed that the large majority of participants selected city B $(76.7 \%)$ against the prediction of the initially most valid cue (i.e., state capital) and that only a minority selected city A (23.3\%). Evidently, TTB was not the predominant strategy applied by our participants.

Again we ran simulations to predict the cue validity ratings in the post-test using the PCS model. Although the task was very different from the previous experiments, we used the same set of parameters as in the previous simulation (see Table 1). We found that the cue validities measured in the post-test were again very well predicted by the model (see Table 2). 


\section{Discussion}

The results of the third study corroborate the predictions of our PCS approach. Cue validities were changed in the process of probabilistic inference. Choices indicated that participants employed a complex decision strategy rather than relying on one reason, as being suggested, for instance, by the TTB heuristic. These results were obtained in a different task and, hence, rule out the possibility that our previous findings hold only for a specific type of task. Moreover, we could rule out potential misgivings about the adequacy of the measure of cue validities used in the prior studies. We could replicate prior results even by assessing participants' beliefs about the environment (i.e., conditional likelihoods) instead of ratings of cue usage.

\section{General Discussion}

We studied the stability of cue validities in binary probabilistic inferences which are a special kind of judgment. From the PCS approach we derived the assumption that cue validities are changed during the process of making a judgment to form a consistent representation of the given pieces of information. Findings from the three experiments using a within-subjects design corroborate the PCS-hypothesis. We observed strong coherence shifts: The subjective validity of cues supporting the favored option is increased; the subjective validity of cues that speak against the favored option is decreased. The first two experiments show that such changes can be observed in tasks for which comprehensive learning experiences can be expected. The third experiment indicates that these coherence shifts also occur in tasks for which is has been claimed that fast-and-frugal heuristics such as the TTB heuristic are applied. All three experiments illustrate that coherence shifts are not limited to contexts in which the material allows to construct stories about the situation (cf. Pennington \& Hastie, 1992) but that they occur in very simple probabilistic inference tasks as well. Furthermore, it was demonstrated that coherence shifts can be found for subjective cue validity ratings based on direct estimations of cue usage as well as for estimations of objective cue validities (i.e., beliefs). In simulations of data on the level of individuals, we could show that the PCS model predicts their cue validity ratings in the post-test very well and better than heuristics and other models that assume stable cue validities.

The second and third experiments indicate that coherence shifts are initiated before an option is selected and before an explicit judgment is made. Thus, shifts in validities cannot be entirely attributed to post-decisional reduction of dissonance (Festinger, 1964; see also Simon \& Holyoak, 2002). The findings converge with those obtained in recent studies on multiattribute choice and legal judgments (e.g., Simon et al., 2004; Simon, Snow, \& Read, 2004; Simon, 2004). They add into an accumulating body of evidence supporting the validity of a connectionist approach to judgment and decision making (Glöckner \& Betsch, 2008a; 2008b; 2008c; Holyoak \& Simon, 1999; Simon et al., 2004). The evidence is in line with findings from other recent studies on probabilistic inference tasks that show that the PCS model pre- 
dicts choices, response times and confidence ratings in certain environments better than fastand-frugal heuristics (Glöckner, 2006; 2007; cf. Glöckner \& Betsch, 2008a; however, see also Bröder \& Gaissmaier, 2007). The fact that coherence shifts are not only observed in preferential decisions, but also in probabilistic judgments, supports the view that constraint satisfaction mechanisms might be a very general mechanism playing an important role in a variety of cognitive processes (Holyoak \& Simon, 1999; Holyoak \& Thagard, 1989; Kunda \& Thagard, 1996; McClelland \& Rumelhart, 1981; Read \& Miller, 1998; Read, Vanman, \& Miller, 1997).

In line with earlier findings (e.g., Holyoak \& Simon, 1999), our results challenge the notion of non-reciprocal judgment and decision making - one of the implicit assumptions of virtually all of the heuristics and strategies that are currently discussed for probabilistic inferences. Commonly, these heuristics start from the information as a given parameter and infer the criterion from it. Processes of restructuring of cues are not part of these strategies. Our findings, however, suggest that individuals take the entire set of information into account and actively change predictors to form a consistent representation of the task. As such, probabilistic inferences seem to involve holistic and reciprocal processes.

\section{Is the PCS mechanisms another fast-and-frugal heuristic?}

What are the implications of our work for theorizing in judgment and decision making? On first glance, our findings seem to conflict with one of the core assumptions of the fast and frugal heuristics approach: "Fast and frugal heuristics are based on (...) heuristic principles such as (...) one-reason decision making" (Goldstein \& Gigerenzer, 1999, p.58).

Clearly, the PCS-approach assumes and the present findings demonstrate the direct opposite. Rather than considering the most important cue only, individuals take the entire picture of the given set of information into account before making a decision.

Note, however, that proponents of the fast-frugal heuristics approach never made any assumptions about the number and the type of strategies that can be part of the heuristic toolbox. Accordingly, this box is a flexible storage device. It provides almost unlimited space for any finding on human decision processes simply because one can always launch another heuristic to account for decision processes not yet described by existing tools in the box. Consequently, one might "integrate" the present findings by cramming a "PCS-heuristic" into the toolbox and any spoil of conflicts would disappear, at least from the viewpoint of the adaptive toolbox approach. $^{8}$

We hasten to add that we do not see the PCS-model as another entry to this toolbox. It is our firm conviction that the persistent accumulation of heuristics is at best of doubtful merit for

8 We are indebted to an anonymous reviewer for directing our attention to this policy of theorizing and its consequences for scientific advance. 
scientific progress. Any theorist striving for increasing the power of scientific prediction soon must realize that the more a theory prohibits, the more it says about our world (cf. Popper, 1986, p.96). If we violate this basic logical principle in theory formulation we will arrive at models that may describe any kind of empirical observation from hindsight though will fail to make any precise predictions ex ante. The unconstrained readiness of the fast-and-frugal heuristics approach to spy out new heuristics runs into the risk of ending with an anything-goesmodel. To be sure, this is not the intention of the architects of this approach. On many occasions they announced that determining conditions for strategy application is one of the major goals on their research agenda (e.g., Gigerenzer et al., 1999, p.16, pp. 141, p. 364). Unfortunately, this goal seems to be quite difficult to reach (cf. Goldstein et al., 2001, p.188) which we will discuss next.

\section{The strategy selection problem}

At the empirical level, the pattern of findings concerning strategy selection is mixed and sometimes even contradictory (e.g., Bröder \& Newell, 2008). For example, there is evidence supporting the view that individuals are able to learn strategies based on appropriate feedback (e.g., Rieskamp \& Otto, 2006). Conversely, Bröder and Schiffer (2006a) provided evidence indicating that individuals maintain strategies even though feedback informs them that their preferred strategy is maladaptive (but see Rieskamp, 2008, for a discussion). As another example, consider the conditions for application of one-reason lexicographic strategies (LEX, TTB). Simulations have shown that this type of strategy is most effective in noncompensatory environments and especially when the decision process is constrained, for instance, by time limits (e.g., Payne, Bettman, \& Johnson, 1988; Gigerenzer \& Goldstein, 1999). Indeed, there are some studies indicating that individuals more frequently apply this type of strategy under the described conditions if information is presented in a hidden matrix (mouselab studies, e.g., Payne, Bettman \& Johnson, 1988; 1992). Contrary to these results, Glöckner and Betsch (2008a) found that even under time constraints and in non-compensatory environments, individuals process information in a compensatory and holistic fashion (as predicted by the PCS model) if the information is presented in an open matrix. These few examples illustrate that condition-seeking has not, so far, been a fast and frugal strategy to advance our understanding of the mechanism underlying choice between heuristics. Not surprisingly, at the theoretical level, the fast-and-frugal heuristics approach still lacks general premises that would allow us to derive clear-cut predictions when an individual will select a specific heuristic (cf. Newell \& Bröder, 2008).

One might conjecture that the search for conditions is still at its beginning. Actually, the quest for conditions arose over three decades ago, when the notion of contingent decision making and the problem of strategy choice entered the arena of the judgment and decision making literature (e.g., Beach \& Mitchell, 1978; Payne, 1982). The persistent identification of new 
heuristics renders the problem even more difficult. By now, it is hard to overlook the wealth of heuristics described in the literature and virtually impossible to consider all these strategies at the same time in an empirical study.

\section{Single-strategy models as an alternative view}

In sharp contrast to the fast-frugal heuristics approach, single-strategy models start from the basic assumption that individuals apply one all-purpose rule when making decisions (see Betsch et al., 2002; Newell \& Bröder, 2008; for overviews). Single-strategy models do not neglect that information acquisition varies substantially across tasks, domains and people. They do not assume, however, that variations in search pattern are indicative for underlying decision processes. Regardless how and to what extent individuals search for information in the environment, they are assumed to feed the gathered information into the same processing mechanism. For example, the weighted-additive decision rule underlying utility theory can also be applied to subsets of information by setting weights at a constant or simply leaving out consideration of further information. As such, the LEX strategy, for example, can be considered to involve an application of the WADD decision rule under the constraint that only one value for each option is considered (e.g., Bergert \& Nosofsky, 2007).

Recently, we outlined an integrative model based on our PCS approach that accounts for choices both at the option and at the level of search behavior (Glöckner and Betsch, 2008c). By spelling out the interaction of automatic process (responsible for operating the PCSdecision rule) and deliberate process (responsible for active search, production and change of information), the model explains the entire decision process in terms of a sequence of choices. At the phenomenological level, these sequences may appear as manifestations of different decision strategies or heuristics. In terms of the model, however, the underlying decision processes always capitalize on one all-purpose rule that operates in a holistic, compensatory and recursive fashion as described by the PCS algorithm.

Against the background of the influential bounded rationality argument (Simon, 1955), however, the question arises how the mind can perform such complex computations that take even modern computers several seconds to solve. The PCS approach suggests that people use automatic processes that have evolved from more basic processes of perception. Not incidentally, the PCS model (like most other current parallel constraint models) was developed on the basic algorithm proposed by McClelland and Rumelhart (1981) to account for word perception. As Maule (2005) pointed out, a central theme in future research on judgment and decision making will be the question of how individuals perceive and represent the given information. Our research puts forward that the automatic system does a great deal of work in restructuring given information. Hence, the fundamental argument of Herbert Simon $(1955,1982)$, who stated that people do not have the cognitive capacity to perform complex computations, 
might have to be qualified by adding "serially and deliberately." However, reading Simon closely reveals that he already anticipated this possibility:

My first empirical proposition is that there is a complete lack of evidence that, in actual choice situations of any complexity, these [EU] computations can be, or are in fact, performed... but we cannot, of course, rule out the possibility that the unconscious is a better decision-maker than the conscious.

(Herbert Simon, 1955, p.104) 


\section{References}

Beach, L. R., \& Mitchell, T. R. (1978). A contingency model for the selection of decision strategies. Academy of Management Review, 3, 439-449.

Bergert, F. B., \& Nosofsky, R. M. (2007). A response-time approach to comparing Generalized Rational and Take-the-Best models of decision making. Journal of Experimental Psychology: Learning, Memory, and Cognition, 33, 107-129.

Betsch, T., Haberstroh, S., \& Höhle, C. (2002). Explaining routinized decision making - a review of theories and models. Theory and Psychology, 12, 453-488.

Betsch, T., Haberstroh, S., Glöckner, A., Haar, T., \& Fiedler, K. (2001). The effects of routine strength on adaptation and information search in recurrent decision making. Organizational Behavior and Human Decision Processes, 84, 23-53.

Betsch, T. (2005). Preference theory: An affect-based approach to recurrent decision making. In T. Betsch \& S. Haberstroh (Eds.), The routines of decision making. Mahwah, NJ: Lawrence Erlbaum.

Bröder, A. (2000). Assessing the empirical validity of the "take-the-best" heuristic as a model of human probabilistic inference. Journal of Experimental Psychology: Learning, Memory, and Cognition, 26, 1332-1346.

Bröder, A. (2003). Decision making with the "Adaptive Toolbox": Influence of environmental structure, intelligence, and working memory load. Journal of Experimental Psychology: Learning, Memory, and Cognition, 29, 611-625.

Bröder, A. \& Newell, B.R. (2008). Challenging some common beliefs about cognitive costs: Empirical work within the adaptive toolbox metaphor. Judgment and Decision Making, 3, 195-204.

Bröder, A., \& Schiffer, S. (2003). Take The Best versus simultaneous feature matching: Probabilistic inferences from memory and effects of reprensentation format. Journal of Experimental Psychology: General, 132, 277-293.

Bröder, A., \& Schiffer, S. (2006a). Adaptive flexibility and maladaptive routines in selecting fast and frugal decision strategies. Journal of Experimental Psychology: Learning, Memory, and Cognition, 32, 904-918.

Bröder, A., \& Schiffer, S. (2006b). Stimulus format and working memory in fast and frugal strategy selection. Journal of Behavioral Decision Making, 19, 361-380.

Bröder, A., \& Gaissmaier, W. (2007). Sequential processing of cues in memory-based multiattribute decisions. Psychonomic Bulletin \& Review, 14, 895-900. 
Brownstein, A. L. (2003). Biased predecision processing. Psychological Bulletin, 129, 545568.

Brownstein, A. L., Read, S. J., \& Simon, D. (2004). Bias at the racetrack: Effects of individual expertise and task importance on predecision reevaluation of alternatives. Personality and Social Psychology Bulletin, 30, 891-904.

Brunswik, E. (1955). Representative design and the probability theory in a functional psychology. Psychological Review, 62, 193-217.

Busemeyer, J. R., \& Townsend, J. T. (1993). Decision field theory: A dynamic cognitive approach to decision making in an uncertain environment. Psychological Review, 100, 432-459.

Busemeyer, J. R., \& Johnson, J. G. (2004). Computational models of decision making. In D. Koehler and N. Harvey (Eds.), Handbook of judgment and decision making (pp. 133154). Oxford, UK: Blackwell.

Carlson, K. A., \& Russo, J. E. (2001). Biased interpretation of evidence by mock jurors. Journal of Experimental Psychology: Applied, 7, 91-103.

Czerlinski, J., Gigerenzer, G., \& Goldstein, D. G. (1999). How good are simple heuristics? In G. Gigerenzer, P. M. Todd, \& the ABC Research Group, Simple heuristics that make us smart (pp. 97-118). New York: Oxford University Press.

Dawes, R. M. (1998). Behavioral decision making and judgment. In D.T. Gilbert, S.T. Fiske \& G. Lindzey (Eds.), The handbook of social psychology - 4th ed. (Vol. 1, p. 497548). Boston, MA: McGraw-Hill.

Doherty, M. E., \& Brehmer, B. (1997). The paramorphic representation of clinical judgment: A thirty-year retrospective. In W. M. Goldstein \& R. M. Hogarth (Eds.), Research on judgment and decision making: Currents, connections, and controversies (pp. 537-551). New York: Cambridge University Press.

Dougherty, M. R. P., Gettys, C. F., \& Ogden, E. E. (1999). MINERVA-DM: A memory process model for judgments of likelihood. Psychological Review, 106, 108-209.

Edwards, W. (1954). The theory of decision making. Psychological Bulletin, 51, 380-417.

Egan, L. C., Santos, L. R., \& Bloom, P. (2007). The origins of cognitive dissonance: Evidence from children and monkeys. Psychological Science, 18, 978-983.

Festinger, L. (1964). Conflict, decision, and dissonance. Stanford, CA: Stanford University Press. 
Fishburn, P. C. (1974). Lexicographic orders, utilities, and decision rules: A survey. Management Science, 20, 1442-1472.

Frey, D. (1981). Informationssuche und Informationsbewertung bei Entscheidungen [Information search and evaluation in decision making]. Bern: Huber.

Gigerenzer, G., Hoffrage, U., \& Kleinbölting, H. (1991). Probabilistic mental models: A Brunswikian theory of confidence. Psychological Review, 98, 506-528.

Gigerenzer, G., \& Goldstein, D. G. (1996). Reasoning the fast and frugal way: Models of bounded rationality. Psychological Review, 103, 650-669.

Gigerenzer, G., Todd, P. M., \& the ABC Group (1999). Simple heuristics that make us smart. New York: Oxford University Press.

Gigerenzer, G., \& Goldstein, D. G. (1999). Betting on one good reason: The take the best heuristic. In G. Gigerenzer, P. M. Todd, \& the ABC Research Group, Simple heuristics that make us smart (pp. 75-95). New York: Oxford University Press.

Gigerenzer, G. (2004). Fast and frugal heuristics: The tools of bounded rationality. In: D. Koehler, \& N. Harvey (Eds.), Handbook of judgment and decision making (pp. 62-88). Oxford, UK: Blackwell.

Gilbert, D. (1991). How mental systems believe. American Psychologist, 46, 107-119.

Gilovich, T., Griffin, D., \& Kahneman, D. (Eds.) (2002). Heuristics and biases: The psychology of intuitive judgment. Cambridge, MA: Cambridge University Press.

Glöckner, A. (2006). Automatische Prozesse bei Entscheidungen [Automatic processes in decision making]. Hamburg: Kovac.

Glöckner, A. (2007). Does intuition beat fast and frugal heuristics? A systematic empirical analysis. In H. Plessner, C. Betsch \& T. Betsch (Eds.), Intuition in judgment and decision making (pp. 309-325). Mahwah, NJ: Lawrence Erlbaum.

Glöckner, A., \& Betsch, T. (2008a). Multiple-reason decision making based on automatic processing. Journal of Experimental Psychology: Learning, Memory, and Cognition, 34, 1055-1075.

Glöckner, A., \& Betsch, T. (2008b). Do people make decisions under risk based on ignorance? An empirical test of the Priority Heuristic against Cumulative Prospect Theory. Organizational Behavior and Human Decision Processes, 107, 75-95. 
Glöckner, A., \& Betsch, T. (2008c). Modeling option and strategy choices with connectionist networks: Towards an integrative model of automatic and deliberate decision making. Judgment and Decision Making, 3, 215-228.

Glöckner, A., \& Engel, C. (2008). Can we trust intuitive jurors? An experimental analysis. MPI Collective Goods Preprint, No. 38. Available at SSRN: http://ssrn.com/abstract $=1307580$.

Goldstein, D. G., Gigerenzer, G, Hogarth, R.M., Kacelnik, A., Kareev, Y., Klein, G.,

Martignon, L., Payne, J.W., \& Schlag, K.H. (2001). Group report: Why and when do simple heuristics work? In G. Gigerenzer \& R. Selten (eds.), Bounded rationality - the adaptive toolbox (pp. 123-145). Cambridge, MA: MIT Press.

Goldstein, D. G., \& Gigerenzer, G. (2002). Models of ecological rationality: The recognition heuristic. Psychological Review, 109, 75-90.

Goldstein, D. G., \& Gigerenzer, G. (1999). The recognition heuristic - how ignorance makes us smart? In G. Gigerenzer, P.M. Todd and the ABC Research Group (Eds.), Simple heuristics that make us smart (pp. 37-58). New York, NY: Oxford University Press.

Goldstein, W. M., \& Hogarth, R. M. (1997). Judgment and decision research: Some historical context. In W. M. Goldstein \& R. M. Hogarth (Eds.), Research on judgment and decision making: Currents, connections, and controversies (pp. 3-65). New York: Cambridge University Press.

Gould, W., Pitblado, J., \& Sribney, W. (2006). Maximum Likelihood Estimation with Stata (3rd ed.). College Station, TX: Stata Press.

Hayes, A. F., \& Cai, L. (2007). Using heteroskedasticity-consistent standard error estimators in OLS regression: An introduction and software implementation. Behavior Research Methods, 39, 709-722.

Hertwig, R., Hoffrage, U., \& Martignon L. (1999). Quick estimation: Letting the environment do the work. In G. Gigerenzer, P. M. Todd and the ABC Research Group (Eds.), Simple heuristics that make us smart (pp. 209-234). Oxford: Oxford University Press.

Holyoak, K. J., \& Simon, D. (1999). Bidirectional reasoning in decision making by constraint satisfaction. Journal of Experimental Psychology: General, 128, 3-31.

Holyoak, K. J., \& Thagard, P. (1989). Analogical mapping by constraint satisfaction. Cognitive Science, 13, 295-355.

Kahneman, D., Slovic, P., \& Tversky, A. (Eds.) (1982). Judgment under uncertainty: Heuristics and biases. Cambridge, MA: Cambridge University Press. 
Kahneman, D. \& Frederick, S. (2002). Representativeness revisited: attribute substitution in intuitive judgment. In T. Gilovich, D. Griffin \& D. Kahneman (Eds.), Heuristics and biases: The psychology of intuitive judgment (pp. 49-81). New York: Cambridge University Press.

Keeney, R. L., \& Raiffa, H. (1976). Decisions with multiple objectives: Preferences and value tradeoffs. New York: Cambridge University Press.

Kunda, Z., \& Thagard, P. (1996). Forming impressions from stereotypes, traits, and behaviors: A parallel-constraint-satisfaction theory. Psychological Review, 103, 284-308.

Lopes, L. L. (1992). Three misleading assumptions in the customary rhetoric of the bias literature. Theory \& Psychology, 2, 231-236.

Maule, J. (2005). Re-Framing decision framing. Presidential address at the 20th Biennial Conference on Subjective Probability, Utility and Decision Making, August 22-24, Stockholm, Sweden.

McClelland, J. L., \& Rumelhart, D. E. (1981). An interactive model of context effects in letter perception. Part 1. An account of basic findings. Psychological Review, 88, 375-407.

Montgomery, H. (1989). From cognition to action: The search for dominance in decision making. In H. Montgomery \& O. Svenson (Eds.), Process and structure in human decision making (pp. 23-49). New York: Wiley.

Newell, B. R. \& Bröder, A. (2008). Cognitive processes, models and metaphors in decision research. Judgment and Decision Making, 3, 205-214.

Newell, B. R., Weston, N. J., \& Shanks, D. R. (2003). Empirical test of fast-and-frugal heuristic: not everyone "takes-the-best". Organizational Behavior and Human Decision Processes, 91, 82-96.

Nisbett, R. E., \& Wilson, T. D. (1977). Telling more than we can know: Verbal reports on mental processes. Psychological Review, 84, 231-259.

Payne, J. W. (1982). Contingent decision behavior. Psychological Bulletin, 92, 382-402.

Payne, J. W., Bettman, J. R., \& Johnson, E. J. (1988). Adaptive strategy selection in decision making. Journal of Experimental Psychology: Learning, Memory, \& Cognition, 14, 534-552.

Payne, J. W., Bettman, J. R., \& Johnson, E. J. (1992). Behavioral decision research: A constructive processing perspective. Annual Review Psychology, 43, 87-131. 
Pennington, N., \& Hastie, R. (1992). Explaining the evidence: Tests of the Story Model for juror decision making. Journal of Personality and Social Psychology, 62, 189-206.

Popper, K. (1989). Logik der Forschung [The logic of scientific discovery ] ( $9^{\text {th }}$ edition). Tübingen: J.C.B. Mohr.

Read, S. J., Vanman, E. J., \& Miller, L. C. (1997). Connectionism, parallel constraint satisfaction and gestalt principles: (Re)introducting cognitive dynamics to social psychology. Personality and Social Psychology Review, 1, 26-53.

Read, S. J. \& Miller, L. C. (1998). On the dynamic construction of meaning: An interactive activation and competition model of social perception. In S. J. Read \& L. C. Miller (Eds.), Connectionist models of social reasoning and social behavior (pp. 27-70), Mahwah, NJ: Lawrence Erlbaum.

Rieskamp, J., \& Hoffrage, U. (1999). When do people use simple heuristics, and how can we tell? In G. Gigerenzer, P. M. Todd and the ABC Research Group (Eds.), Simple heuristics that make us smart (pp. 141-167). New York, NY: Oxford University Press.

Rieskamp, J. (2006). Perspectives of probabilistic inferences: Reinforcement learning and an adaptive network compared. Journal of Experimental Psychology: Learning, Memory, and Cognition, 32, 1355-1370.

Rieskamp, J., \& Otto, P. E. (2006). SSL: A theory of how people learn to select strategies. Journal of Experimental Psychology: General, 135, 207-236.

Russo, J. E. \& Dosher, B. A. (1983). Strategies for multiattribute binary choice. Journal of Experimental Psychology: Learning, Memory and Cognition, 9, 676-696.

Russo, J. E., Meloy, M. G., \& Medvec, V. H. (1998). Predecisional distortion of product information. Journal of Marketing Research, 35, 438-452.

Shultz, T. R., \& Lepper, M. R. (1996). Cognitive dissonance reduction as constraint satisfaction. Psychological Review, 103, 219-240.

Simon, D., \& Holyoak, K. J. (2002). Structural dynamics of cognition: from consistency theory to constraint satisfaction. Personality and Social Psychology Review, 6, 283-294.

Simon, D., Krawczyk, D. C., \& Holyoak, K. J. (2004). Construction of preferences by constraint satisfaction. Psychological Science, 15, 331-336.

Simon, D. (2004). A third view of the black box: cognitive coherence in legal decision making. University of Chicago Law Review, 71, 511-586. 
Simon, D., Snow, C. J., \& Read, S. J. (2004). The redux of cognitive consistency theories: evidence judgments by constraint satisfaction. Journal of Personality and Social Psychology, 86, 814-837.

Simon, D., Krawczyk, D. C., Bleicher, A., \& Holyoak, K. J. (2008). The transience of constructed preferences. Journal of Behavioral Decision Making, 21, 1-14.

Simon, H. A. (1955). A behavioral model of rational choice. The Quarterly Journal of Economics, 69, 99-118.

Simon, H. A. (1982). Models of bounded rationality. Cambridge, MA: MIT Press.

Slovic, P. (1995). The construction of preference. American Psychologist, 50, 364-371.

Svenson, O. (1992). Differentiation and consolidation theory of human decision making: A frame of reference for the study of pre- and post-decision processes. Acta Psychologica, 80, 143-168.

Thagard, P. (1989). Explanatory coherence. Behavioral and Brain Sciences, 12, 435-502.

Thagard, P. \& Millgram, E. (1995). Inference to the best plan: A coherence theory of decision. In A. Ram \& D. B. Leake (Eds.), Goal-driven learning (pp. 439-454). Cambridge, MA: MIT Press.

Thagard, P. (2003). Why wasn't O.J. convicted? Emotional coherence in legal inference. Cognition \& Emotion, 17, 361-383.

Todd, P. M., \& Gigerenzer, G. (2003). Bounding rationality to the world. Journal of Economic Psychology, 24, 143-165.

Usher, M., \& McClelland, J. L. (2001). The time course of perceptual choice: The leaky, competing accumulator model. Psychological Review, 108, 550-592.

Usher, M., \& McClelland, J. L. (2004). Loss Aversion and Inhibition in Dynamical Models of Multialternative Choice. Psychological Review, 111, 757-769.

Weber, E. U., Goldstein, W. M., \& Barlas, S. (1995). And let us not forget memory: The role of memory processes and techniques in the study of judgment and choice. In J. R. Busemeyer, R. Hastie, \& D. L. Medin (Eds.), Decision making from a perspective of cognitive psychology (pp. 38 - 81). San Diego, CA: Academic Press.

Yates, J. F. (2003). Decision management. San Francisco: Jossey-Bass. 
Yates, J. F., \& Tschirhart, M. D. (2006). Decision-Making Expertise. In K. A. Ericsson, N. Charness, P. J. Feltovich \& R. R. Hoffman (Eds.), The Cambridge handbook of expertise and expert performance (pp. 421-438). New York: Cambridge University Press. 